\title{
PENGARUH CORPORATE SOCIAL RESPONSIBILITY TERHADAP WILLINGNESS TO PURCHASE DENGAN BRAND IMAGE SEBAGAI VARIABEL MEDIASI (STUDI PADA KAMPUNG DONGENG TEH SISRI)
}

\author{
Helen \\ Program Studi Magister Manajemen Universitas Tarumanagara \\ hello.helenlie@gmail.com \\ Hetty Karunia Tunjungsari \\ Program Studi Magister Manajemen Universitas Tarumanagara \\ Masuk : 24-11-2019, revisi : 18-12-2019 diterima untuk diterbitkan : 19-12-2019
}

\begin{abstract}
The purpose of this study is to obtain an analysis of marketing initiatives through corporate social responsibility to increase willingness to purchase that gives effect through brand image. Especially for brands that are experiencing a brand image crisis, through this research, one of the steps that can be taken is through corporate social responsibility. The research sample uses a questionnaire method consisting of 230 respondents in two elementary schools that were held in the Kampung Dongeng Teh Sisri Village. Hypothesis testing uses multiple linear regression statistical methods. The results showed that corporate social responsibility had a positive effect on willingness to purchase both directly and through brand image, corporate social responsibility had a positive effect on brand image, then brand image also had a positive effect on willingness to purchase.
\end{abstract}

Abstrak : Tujuan penelitian ini adalah untuk memperoleh analisis marketing inisiatif melalui corporate social responsibility untuk meningkatkan willingness to purchase yang memberi efek melalui brand image. Terlebih bagi brand yang sedang mengalami krisis brand image, melalui penelitian ini didapatkan salah satu langkah yang bisa diambil adalah melalui corporate social responsibility. Sampel penelitian menggunakan metode kuesioner yang terdiri dari 230 responden di dua sekolah dasar yang diadakan Kampung Dongeng Teh Sisri. Pengujian hipotesis menggunakan metode statistik regresi linear berganda. Hasil penelitian menunjukkan bahwa corporate social responsibility berpengaruh positif terhadap willingness to purchase baik langsung mapun melalui brand image, corporate social responsibility berpengaruh positif terhadap brand image, kemudian brand image juga berpengaruh positif terhadap willingness to purchase.

Keywords : corporate social responsibility, brand image, willingness to purchase

\section{PENDAHULUAN}

Kegiatannya marketing sering kali disulitkan oleh brand image yang tidak terbangun baik. Brand image sendiri menurut (Keller 3 : 1993) adalah persepsi mengenai sebuah brand yang merupakan refleksi dari brand asosiasi yang ada diingatan konsumen. Dalam mencapai brand image positif dapat melakukan salah satu cara yaitu Corporate Social Responsibility.

Corporate Social Responsibility diartikan oleh Frederick, yang mengatakan bahwa corporate social responsibility menunjukkan kapasitas suatu korporasi dalam memberikan respons terhadap tekanan sosial, tindakan yang nyata sebagai suatu tanggapan atau untuk memperoleh bentuk tanggapan secara umum bagi masyarakat merupakan fokus dari konsep corporate social responsibility (Solihin, $2008: 71$ ).

Bagi marketing, selanjutnya setelah membentuk brand image yang diinginkan, diharapkan target konsumen juga memiliki buying willingness, menurut (Dodds, Monron \& 
Grewal, 1991) dalam jurnal Wu dan Wang (2014). Impact of CSR Perseption on Brand Image, Brand Attitude, and Buying Willingness : A Study of a Globe Cafe. Internasional Journal of Marketing Studies, 6 (6), 43-56 adalah kemungkinan konsumen membeli sebuah produk. Semakin tinggi kemungkinan konsumen membeli maka semakin tinggi pula pembelian secara nyata (Schiffman \& Kanuk, 2000). Hal ini sejalan dengan apa yang dilakukan oleh objek penelitian penulis yaitu Teh Sisri. Teh Sisri beberapa tahun lalu mengalami keterpurukkan brand image, target konsumen Teh Sisri tidak memandang produk atau brand ini secara positif sehingga berdampak pada penjualan yang terus menurun.

Merujuk pada fakta diatas, peneliti tertarik untuk mengetahui pengaruh CSR yang dilakukan oleh Teh Sisri untuk memperbaiki brand image dan willingness to purchase konsumennya.

\section{TINJAUAN LITERATUR}

\section{Corporate Social Responsibility}

Corporate social responsibility ini dianggap sebagai sebuah kesukarelaan perusahaan dengan mengintegrasikan nilai kepedulian sosial dan lingkungannya ke dalam aktivitas bisnis serta interaksi dengan para stakeholder (Prajarto, 2012 : 24). Kotler dan Lee (2006) dalam buku (Solihin 2008 : 131) mengatakan bahwa ada enam kategori corporate social responsibility yaitu cause promotion, cause related promotion, corporate social marketing, corporate philantrophy, community volunteering, dan community development.

\section{Brand Image}

Persepsi atau kepercayaan yang dianut oleh konsumen yang mencerminkan dalam hubungan yang terjadi pada ingatan mereka menurut Keller (2008). Menurut Keller (2008, 5758) faktor-faktor yang mendukung terbentuknya citra merek antara lain ialah kekuatan asosiasi merek, keunggulan asosiasi merek, dan keunikan asosiasi merek.

\section{Willingness To Purchase}

Probabilitas kemauan konsumen untuk membeli produk menurut Wu dan Wang (2014). Variabel yang menentukan keputusan untuk membeli antara lain Individual influence, Environment influences, Psychological processes.

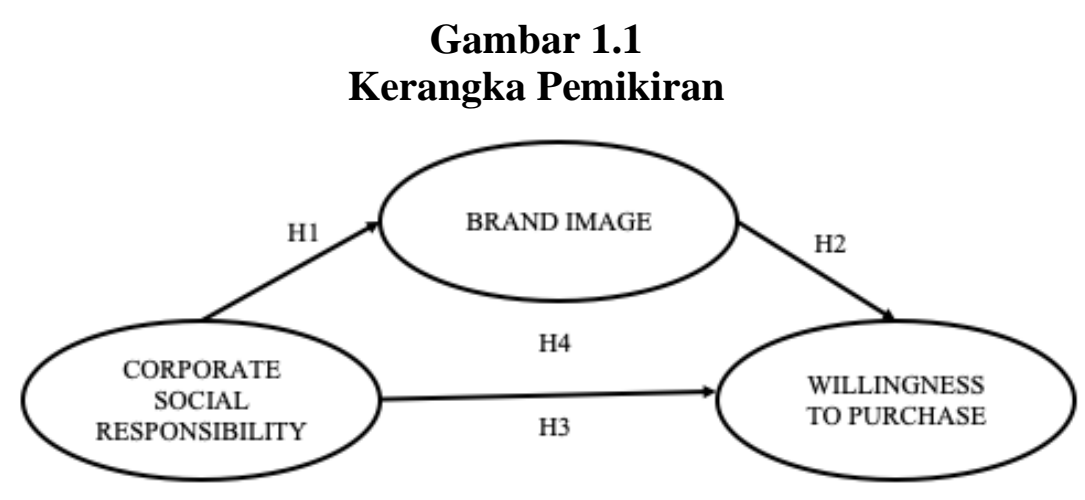

\section{Hipotesis}

H1 : Terdapat pengaruh yang positif dan signifikan antara corporate social responsibility terhadap brand image

$\mathrm{H} 2$ : Terdapat pengaruh yang positif dan signifikan antara corporate social responsibility terhadap willingness to purchase.

H3 : Terdapat pengaruh yang positif dan signifikan antara brand image terhadap willingness to purchase.

$\mathrm{H} 4$ : Terdapat pengaruh yang positif dan signifikan antara corporate social responsibility terhadap willingness to purchase melalui brand image 


\section{METODE PENELITIAN}

Jenis penelitian yang dilakukan adalah penelitian deskriptif kuantitatif. Periode penelitian ini adalah Januari 2019 - Mei 2019. Data yang digunakan dalam penelitian ini adalah data primer dan data sekunder. Kuesioner diberikan kepada 230 responden di dua sekolah dasar yaitu SDN Tanah Sereal 01 dan SDN Palmerah 09 Pagi. Penelitian ini menggunakan Teknik analisis model regresi linear berganda. Model regresi linear berganda ini digunakan untuk mengetahui bagaimana pengaruh Corporate Social Responsibility terhadap Willingness To Purchase dengan variabel Brand Image sebagai mediasi.

\section{HASIL PENELITIAN DAN PEMBAHASAN}

Adapun variabel yang diuji dibagi menjadi 2 struktur.

1. Substruktur 1 - Corporate Social Responsibility Pada Brand Image

\section{Gambar 1.2}

\section{Kerangka Pemikiran Substruktur 1}

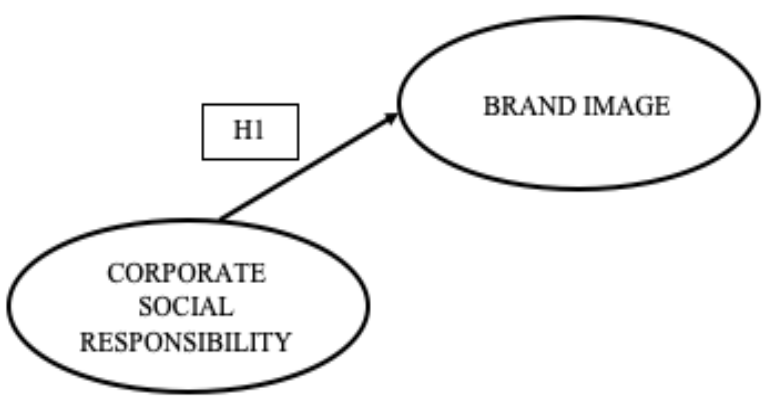

2. Substruktur 2 - Corporate Social Responsibility dan Brand Image Pada Willingness To Purchase

\section{Gambar 1.3}

Kerangka Pemikiran Substruktur 2

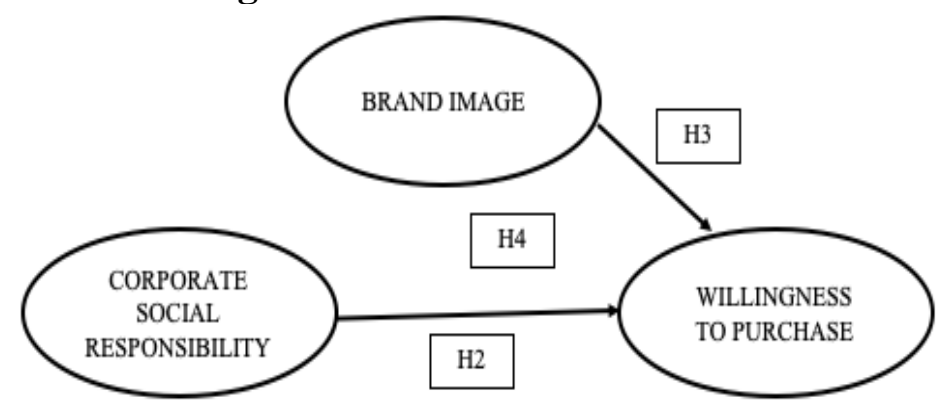

\section{UJI ASUMSI KLASIK}

Substruktur 1 maupun subtruktur 2 menunjukkan bahwa nilai residual terdistribusi secara normal. Data yang tidak menyebar jauh dan cenderung mengikuti garis diagonal. Kemudian tidak ada pola yang jelas serta titik-titik menyebar, sehingga dapat disimpulkan bahwa uji heteroskedastisitas terpenuhi. Selanjutnya berdasarkan hasil uji SPSS variabel memiliki nilai VIF < 10 sehingga dapat disimpulkan bahwa tidak terjadi multikolinearitas (H0 diterima). 


\section{UJI F}

1. Substruktur 1 - Corporate Social Responsibility Pada Brand Image

Tabel 1.1

ANOVA Substruktur 1

\begin{tabular}{|c|c|c|c|c|c|c|}
\hline \multicolumn{7}{|c|}{ ANOVA $^{\mathrm{a}}$} \\
\hline \multicolumn{2}{|c|}{ Model } & $\begin{array}{l}\text { Sum of } \\
\text { Squares }\end{array}$ & df & $\begin{array}{l}\text { Mean } \\
\text { Square }\end{array}$ & $\mathrm{F}$ & Sig. \\
\hline \multirow[t]{3}{*}{1} & Regression & 11596.812 & 1 & 11596.812 & 171.942 & $.000^{\mathrm{b}}$ \\
\hline & Residual & 15377.662 & 228 & 67.446 & & \\
\hline & Total & 26974.474 & 229 & & & \\
\hline \multicolumn{7}{|c|}{ a. Dependent Variable: Brand Image } \\
\hline \multicolumn{7}{|c|}{ b. Predictors: (Constant), Corporate Social Responsibility } \\
\hline
\end{tabular}

Berdasarkan tabel 1.1 dapat diketahui nilai signifikan lebih kecil dari 0,05 atau 5\%. Hal ini berarti hipotesis diterima yaitu terdapat pengaruh signifikan antara corporate social responsibility terhadap brand image.

2. Substruktur 2 - Corporate Social Responsibility dan Brand Image Pada Willingess To Purchase

Tabel 1.2

ANOVA Substruktur 2

\begin{tabular}{|c|c|c|c|c|c|c|}
\hline \multicolumn{7}{|c|}{ ANOVA $^{\mathbf{a}}$} \\
\hline \multicolumn{2}{|c|}{ Model } & $\begin{array}{l}\text { Sum of } \\
\text { Squares }\end{array}$ & df & $\begin{array}{l}\text { Mean } \\
\text { Square }\end{array}$ & & Sig. \\
\hline \multirow[t]{3}{*}{1} & Regression & 1052.382 & 2 & 526.191 & 136.356 & $.000^{\mathrm{b}}$ \\
\hline & Residual & 875.983 & 227 & 3.859 & & \\
\hline & Total & 1928.365 & 229 & & & \\
\hline
\end{tabular}

Berdasarkan tabel 1.2 dapat diketahui nilai signifikan lebih kecild ari 0,05 atau 5\%. Hal ini berarti hipotesis diterima yaitu terdapat pengaruh signfikan antara corporate social responsibility dan brand image terhadap willingness to purchase.

\section{KOEFISIEN DETERMINASI}

1. Substruktur 1 - Corporate Social Responsibility Pada Brand Image

Tabel 1.3

R Square Substruktur 1

\begin{tabular}{|c|c|c|c|c|}
\hline \multicolumn{5}{|c|}{ Model Summary } \\
\hline Model & $\mathrm{R}$ & R Square & $\begin{array}{l}\text { Adjusted R } \\
\text { Square }\end{array}$ & $\begin{array}{l}\text { Std. Error of } \\
\text { the Estimate }\end{array}$ \\
\hline 1 & $.656^{\mathrm{a}}$ & .430 & .427 & 8.213 \\
\hline
\end{tabular}

Berdasarkan tabel 1.3 nilai koefisien korelasi adalah 0,656 atau 65,6\%. Hal ini berarti corporate social responsibility memiliki hubungan sangat kuat dengan brand image. 
2. Substruktur 2 - Corporate Social Responsibility dan Brand Image Pada Willingess To Purchase

Tabel 1.4

R Square Substruktur 2

\begin{tabular}{|l|c|c|c|c|}
\hline \multicolumn{5}{|c|}{ Model Summary } \\
\hline Model & $\mathrm{R}$ & $\mathrm{R}$ Square & $\begin{array}{c}\text { Adjusted R } \\
\text { Square }\end{array}$ & $\begin{array}{c}\text { Std. Error of the } \\
\text { Estimate }\end{array}$ \\
\hline 1 & $.739^{\mathrm{a}}$ & .546 & .542 & 1.964 \\
\hline
\end{tabular}

Berdasarkan tabel 1.4 nilai koefisien korelasi adalah 0,739 atai 73,9\%. Hal ini berarti corporate social responsibility dan brand image memiliki hubungan sangat kuat dengan willingness to purchase.

\section{UJI T}

1. Substruktur 1 - Corporate Social Responsibility Pada Brand Image

Tabel 1.5

Nilai Signifikansi T Parsial Substruktur 1

\begin{tabular}{|c|c|c|c|c|c|c|}
\hline \multicolumn{7}{|c|}{ Coefficients ${ }^{\mathrm{a}}$} \\
\hline \multirow{2}{*}{\multicolumn{2}{|c|}{ Model }} & \multicolumn{2}{|c|}{$\begin{array}{l}\text { Unstandardized } \\
\text { Coefficients }\end{array}$} & \multirow{3}{*}{$\begin{array}{c}\begin{array}{c}\text { Standardized } \\
\text { Coefficients }\end{array} \\
\text { Beta }\end{array}$} & \multirow[t]{2}{*}{$\mathrm{t}$} & \multirow[t]{2}{*}{ Sig. } \\
\hline & & B & Std. Error & & & \\
\hline \multirow[t]{2}{*}{1} & (Constant) & 18.167 & 2.984 & & 6.088 & .000 \\
\hline & $\begin{array}{l}\text { Corporate Social } \\
\text { Responsibility }\end{array}$ & .840 & .064 & .656 & 13.113 & .000 \\
\hline
\end{tabular}

Berdasarkan Tabel 1.5, maka hasil koefisien tersebut dapat diartikan sebagai berikut:

Besarnya pengaruh Corporate Social Responsibility terhadap Brand Image seperti yang ditunjukkan oleh nilai koefisien dari penelitian, yaitu sebesar 0,656 yang berarti Setiap peningkatan Corporate Social Responsibility sebesar 1 satuan, maka akan meningkatkan Brand Image sebesar 0,656 dengan asumsi bahwa variabel independen lain bernilai tetap.

Berdasarkan hasil uji regresi jalur model 1 sesuai dengan tabel 1.7, untuk selanjutnya persamaan regresi dapat dirumuskan :

$$
\begin{gathered}
\mathbf{Y}_{\mathbf{1}}=\mathbf{0 , 6 5 6} \mathbf{X}_{\mathbf{1}}+\mathbf{0 , 3 4 4} \\
\text { Brand Image }=0,656 \mathrm{CSR}+0,344
\end{gathered}
$$

2. Substruktur 2 - Corporate Social Responsibility dan Brand Image Pada Willingess To Purchase

Tabel 1.6

\begin{tabular}{|c|c|c|c|c|c|c|}
\hline \multicolumn{7}{|c|}{ Coefficients $^{\mathrm{a}}$} \\
\hline \multirow{2}{*}{\multicolumn{2}{|c|}{ Model }} & \multicolumn{2}{|c|}{$\begin{array}{l}\text { Unstandardized } \\
\text { Coefficients }\end{array}$} & \multirow{2}{*}{$\begin{array}{c}\text { Standardized } \\
\text { Coefficients } \\
\text { Beta }\end{array}$} & \multirow[t]{2}{*}{$\mathrm{t}$} & \multirow[t]{2}{*}{ Sig. } \\
\hline & & B & Std. Error & & & \\
\hline \multirow[t]{3}{*}{1} & (Constant) & 3.718 & .770 & & 4.831 & .000 \\
\hline & $\begin{array}{l}\text { Corporate Social } \\
\text { Responsibility }\end{array}$ & .221 & .020 & .646 & 10.901 & .000 \\
\hline & Brand Image & .035 & .016 & .131 & 2.219 & .027 \\
\hline
\end{tabular}

Nilai Signifikansi T Parsial Substruktur 2 
Berdasarkan Tabel 1.6, maka hasil koefisien tersebut dapat diartikan sebagai berikut:

1. Pengaruh Corporate Social Responsibility terhadap Willingness to Purchase

Besarnya pengaruh Corporate Social Responsibility terhadap Willingness to Purchase seperti yang ditunjukkan oleh nilai koefisien dari penelitian, yaitu sebesar 0,646 yang berarti Setiap peningkatan Corporate Social Responsibility sebesar 1 satuan, maka akan meningkatkan Willingness to Purchase sebesar 0,646 dengan asumsi bahwa variabel independen lain bernilai tetap.

2. Pengaruh Brand Image terhadap Willingness to Purchase

Besarnya pengaruh Brand Image terhadap Willingness to Purchase seperti yang ditunjukkan oleh nilai koefisien dari penelitian, yaitu sebesar 0,131 yang berarti Setiap peningkatan Brand Image sebesar 1 satuan, maka akan meningkatkan Willingness to Purchase sebesar 0,131 dengan asumsi bahwa variabel independen lain bernilai tetap.

Selanjutnya, berdasarkan hasil uji regresi jalur model 2, persamaan regresi dapat dirumuskan sebagai berikut:

$$
\mathrm{Z}=\mathbf{0 , 6 4 6} \mathrm{X}+\mathbf{0 , 1 3 1} \mathrm{Y}+\mathbf{0 , 4 5 4}
$$

Willingness To Purchase $=0,646$ CSR $+0,131$ Brand Image $+0,454$

\section{KESIMPULAN DAN IMPLIKASI}

Berdasarkan hasil penelitian ini penulis dapat menyimpulkan :

1. Corporate social responsibility mempengaruhi brand image dengan berbagai aktivitas kebaikkan yang diberikan, hal ini membuat konsumen terutama anak-anak sebagai konsumen Teh Sisri memberikan respon positif terhadap brand Teh Sisri.

2. Corporate social responsibility mempengaruhi willingness to purchase apabila dilakukan langsung kepada target konsumennya terlebih apabila aktivitas corporate social responsibility yang dilakukan telah membangun brand image brand tersebut.

3. Brand Image mempengaruhi willingness to purchase sehingga brand maupun perusahaan diharapkan dapat terus melaksanakan aktivitas yang dapat meningkatkan reputasi maupun citra baik brand dan perusahaan tersebut.

4. Corporate Social Responsibility dan brand image merupakan sebuah kesatuan yang akan saling mempengaruhi, yang ketika dijalankan berdampak terhadap willingness to purchase. Hal ini lah yang dilaksanakan oleh Teh Sisri.

\section{DAFTAR PUSTAKA}

Keller, K. L. (1993). Conceptualizing, Measuring, and Managing Customer-Based Brand Equity. Journal of Marketing, 57, 1-22.

Solihin, Ismail. (2009). Corporate Social Responsibility. Jakarta : Salemba Empat. Education, 21, (4), 84-89.

Wu dan Wang (2014). Impact of CSR Perception on Brand Image, Brand Attitude, and Buying Willingness : A Study of a Globe Café. Internasional Journal of Marketing Studies 6 (6), 43-56.

Prajarto, Nunung. (2012). CSR Indonesia : Sinergi Pemerintah, Perusahaan, dan Publik. Fakulkas Ilmu Sosial dan Ilmu Politik, Universitas Gadja Mada 